\title{
Treatment of Secondary Sedimentation Tank Wastewater by Fenton Oxidation-Neutralization-Coagulation Sedimentation
}

\author{
Shan Chen, Bin Liu, Cheng-yuan Hu \\ Yancheng Environmental Monitoring Center of Jiangsu province, Jiangsu, 224000, China
}

\begin{abstract}
In this paper, the $\mathrm{COD}_{\mathrm{Cr}}$ index is used as the detection item, and the wastewater from the secondary clarifier of a sewage treatment plant is treated by "Fenton oxidation-neutralization-coagulation sedimentation" method. The results showed that the removal rate of $\mathrm{COD}_{\mathrm{Cr}}$ reached $73.4 \%$ by "Fenton oxidation-neutralization-coagulation precipitation" method. It can be seen that this method can make the wastewater discharge up to the standard and provide data support for better treatment of industrial wastewater in engineering.
\end{abstract}

Keywords Secondary sedimentation tank; CODCr; Fenton oxidation; Up-to-standard emissions

DOI: 10.7176/JEES/9-7-01

Publication date:July $31^{\text {st }} 2019$

\section{Introduction}

The rapid economic development not only promotes social progress, but also brings harm to the environment, which makes pollution become a major problem, among which water pollution is the most important. In order to better control water pollution, China has built sewage treatment plants in cities and towns to treat industrial sewage or domestic sewage, so as to improve water quality ${ }^{[1-4]}$. The secondary sedimentation tank is a key unit of sewage treatment plant, which will directly affect the effluent quality of biochemical treatment system and the concentration of reflux sludge. Its operation status is related to the effluent index ${ }^{[5-6]}$. In this study, activated carbon, coagulant polyaluminium chloride (PAC) and polyacrylamide (PAM) were applied to the comprehensive oxidation method of "Fenton oxidation-neutralization-coagulation sedimentation" ${ }^{[7-12]}$. The secondary sedimentation tank wastewater was treated. By improving the removal rate of CODCr, the wastewater was treated to meet the discharge standards, which provided experimental data support for the water treatment engineering reform.

\section{Experiment}

\subsection{Conventional Water Quality Indicators}

The $\mathrm{pH}$ value was determined by glass electrode method, the chroma was determined by dilution multiple method, the total phosphorus was determined by ammonium molybdate spectrophotometry, and the $\mathrm{COD}_{\mathrm{Cr}}$ was determined by potassium dichromate method ${ }^{[13]}$.

\subsection{Fenton oxidation of wastewater \\ 2.2.1 Catalyst Addition}

The $\mathrm{FeSO}_{4} \cdot 7 \mathrm{H}_{2} \mathrm{O}$ of $0.3 \%$, $0.4 \%$, $0.5 \%, 0.6 \%$ 、 and $0.7 \%$ were added to the beaker with concentrated sulphuric acid to adjust the $\mathrm{pH}$ to 3 and $0.24 \mathrm{~mL}$ of $30 \%$ hydrogen peroxide. After 2 hours of reaction, $0.4 \mathrm{~g} / \mathrm{L}$ calcium hydroxide was added to the beaker. After static precipitation, supernatant was taken to detect $\mathrm{COD}_{\mathrm{Cr}}$. The average value of each water sample was determined twice.

\subsubsection{Fenton reaction time}

Fixed $1.2 \mathrm{~mL}$ hydrogen peroxide dosage and $0.5 \% \mathrm{FeSO} \cdot 7 \mathrm{H} 2 \mathrm{O}$ dosage, the effects of reaction time on fenton oxidation were investigated at $1 \mathrm{~h}, 2 \mathrm{~h}, 3 \mathrm{~h}, 4 \mathrm{~h}, 5 \mathrm{~h}$ and $6 \mathrm{~h}$, respectively. After the experiment, the supernatant was taken to detect CODCr, and the average value of each water sample was determined twice to study the effect of fenton oxidation.

\subsubsection{Agitation method}

Fixed the dosage of $1.2 \mathrm{~mL}$ hydrogen peroxide and $0.5 \% \mathrm{FeSO}_{4} \cdot 7 \mathrm{H}_{2} \mathrm{O}$, and investigated the effects of mechanical stirring and aeration stirring on fenton oxidation. At the same time, the raw water was transferred to the same condition of fenton oxidation $\mathrm{pH}$ about 3 for aeration stripping. The supernatant was taken to detect $\mathrm{COD}_{\mathrm{Cr}}$ after static precipitation, and the average value was obtained twice for each water sample. The reaction time was 2 hours, and the end was adjusted to $\mathrm{pH}$ neutral.

\subsubsection{Adsorption-coagulation after fenton oxidation}

The addition amount of $1.2 \mathrm{~mL}$ hydrogen peroxide and $0.5 \%$ o $\mathrm{FeSO}_{4} \cdot 7 \mathrm{H}_{2} \mathrm{O}$ was fixed, fenton reaction was conducted for $2 \mathrm{~h}$, and the supernatant was separated into two parts for coagulation and sedimentation and adsorption-coagulation and sedimentation secondary treatment. Among them, the coagulation precipitation was added with $0.2 \mathrm{~mL} 10 \% \mathrm{PAC}$ solution and $0.2 \mathrm{~mL} 2.5 \% \mathrm{PAM}$ solution. The flocs were rapidly stirred until the flocs appeared, stopped and stood. After the precipitation, the supernatant was taken to detect $\mathrm{COD}_{\mathrm{Cr}}$. Adsorptionscoagulation precipitation was conducted by adding $0.2 \%$ activated carbon for adsorption reaction for $1 \mathrm{~h}$, adding 
$0.2 \mathrm{~mL} 10 \% \mathrm{PAC}$ solution and $0.2 \mathrm{~mL} 2.5 \% \mathrm{PAM}$ solution, rapidly stirring until the flocs were stopped. After settling, the supernatant was taken to detect $\mathrm{COD}_{\mathrm{Cr}}$, and the average value of each water sample was determined twice.

\subsubsection{Fenton oxidation - neutralization - coagulation precipitation under the best conditions}

Fixed hydrogen peroxide $1.2 \mathrm{~mL}$ dosing quantity and $0.5 \%$ of $\mathrm{FeSO}_{4} \cdot 7 \mathrm{H}_{2} \mathrm{O}$ dosing quantity, fenton reaction $4 \mathrm{~h}$, with the method of mechanical agitation, treated water adsorption - coagulation precipitation of secondary processing, quick stir until floc appear to stop stirring, let stand on clear liquid after precipitation test $\mathrm{COD}_{\mathrm{Cr}}$, determination of average twice.

\section{Results and discussion}

\subsection{Testing results of raw water sample}

According to the method specified in section 1.1 of the original water samples for testing, the original water quality presents a beige, its $\mathrm{pH}, \mathrm{CODCr}$, total phosphorus and chromaticity are shown in Table 1.

Table 1 the second pond water quality inspection situation

\begin{tabular}{ccccc}
\hline Water source & $\mathrm{pH}$ & $\begin{array}{c}\mathrm{COD}_{\mathrm{Cr}} \\
\mathrm{mg} / \mathrm{L}\end{array}$ & Total phosphorus mg/L & $\begin{array}{c}\text { Chroma } \\
\text { Diluted multiples }\end{array}$ \\
\hline Secondary sedimentation tank effluent & 7.77 & 183 & 0.4 & 50 \\
\hline
\end{tabular}

\subsection{Fenton oxidation experiment}

\subsubsection{Oxidation treatment effect after adding catalyst}

As described in 2.2.1, fenton oxidation treatment effect is shown in Fig. 1.

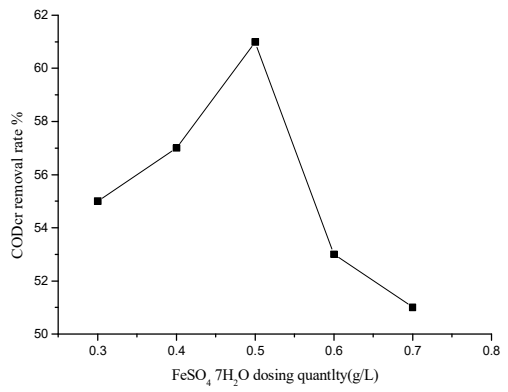

Fig. 1 Influence of $\mathrm{FeSO}_{4} \cdot 7 \mathrm{H}_{2} \mathrm{O}$ dosage on $\mathrm{COD}_{\mathrm{Cr}}$ removal rate

It can be seen from Fig. 1 that the removal rate of $\mathrm{COD}_{\mathrm{Cr}}$ increased first and then decreased with the addition amount of FeSO4-7H2O. When FeSO4-7H2O dosage was $0.3 \%$, $0.4 \%$, $0.5 \%$, $0.6 \%$ and $0.7 \%$ respectively, the removal rates of $\mathrm{COD}_{\mathrm{Cr}}$ measured were $54.7 \%, 57.6 \%, 60.9 \%, 55.2 \%$ and $51.4 \%$, respectively.

When $\mathrm{FeSO}_{4} \cdot 7 \mathrm{H}_{2} \mathrm{O}$ was added at a small dosage, $\mathrm{Fe}^{2+}$ would be oxidized by $\mathrm{H}_{2} \mathrm{O}_{2}$ to $\mathrm{Fe}^{3+}$ and generate a large amount of hydroxyl radicals, which would easily react with refractory organic pollutants in wastewater and decompose them to play the role of flocculation and sedimentation. Therefore, the removal rate of $\mathrm{COD}_{\mathrm{Cr}}$ in wastewater was constantly improved. When the dosage of $\mathrm{FeSO}_{4} \cdot 7 \mathrm{H}_{2} \mathrm{O}$ was gradually increased to more than $0.5 \%$, the high concentration of $\mathrm{Fe}^{2+}$ in the wastewater would consume part of $\mathrm{H}_{2} \mathrm{O}_{2}$, resulting in ineffective decomposition of $\mathrm{H}_{2} \mathrm{O}_{2}$, and the release of $\mathrm{H}_{2} \mathrm{O}_{2}$, which affected the oxidation effect and reduced the removal rate of $\mathrm{COD}_{\mathrm{Cr}}$ in the wastewater. At the same time, excessive $\mathrm{Fe}^{3+}$ generated by $\mathrm{Fe}^{2+}$ oxidation will make the wastewater return to color and cause secondary pollution. Therefore, if the fixed addition amount of hydrogen peroxide was $1.2 \mathrm{~mL}$, the best oxidation treatment effect was obtained by adding $0.5 \%$ o $\mathrm{FeSO}_{4} \cdot 7 \mathrm{H}_{2} \mathrm{O}$.

\subsubsection{Influence of reaction time on oxidation treatment}

As described in 2.2.2, the effect of reaction time on fenton oxidation treatment effect is shown in fig.2. It can be seen from Fig. 2 that the removal rate of $\mathrm{COD}_{\mathrm{Cr}}$ in waste water first increased and then decreased with the increase of reaction time. When the reaction time was $1 \mathrm{~h}, 2 \mathrm{~h}, 3 \mathrm{~h}, 4 \mathrm{~h}, 5 \mathrm{~h}$ and $6 \mathrm{~h}$, respectively, the removal rates of $\mathrm{COD}_{\mathrm{Cr}}$ were $55.1 \%, 59.5 \%, 64.8 \%, 68.5 \%, 67.2 \%$ and $65.8 \%$, respectively.

The length of reaction time in a certain situation directly affects the degree of reaction and whether the reaction can be carried out completely. On the contrary, if the reaction time is too long, the reactor volume will be affected instead of further effects. When the reaction time was less than $4 \mathrm{~h}$, the removal rate curve of $\mathrm{COD}_{\mathrm{Cr}}$ increased rapidly, indicating that fenton's oxidation rate was very fast at this time. Organic matter in wastewater was continuously oxidized with the increase of time, and the concentration of reactant was sufficient to maintain the requirement of reaction rate. However, when the reaction time was longer than $4 \mathrm{~h}$, the reaction gradually became complete, and the removal rate of organic compounds no longer increased with the extension of time. This indicates that when fenton oxidation time was $4 \mathrm{~h}$, the removal rate of $\mathrm{COD}_{\mathrm{Cr}}$ in waste water was the highest, and the oxidation treatment had the best effect. 


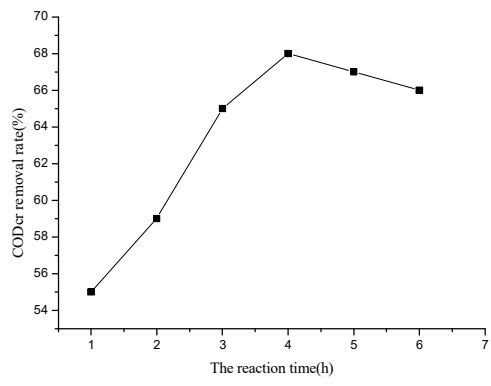

Fig. 2 Effect of reaction time on $\mathrm{COD}_{\mathrm{Cr}}$ removal rate

\subsubsection{Influence of stirring mode on oxidation effect}

As described in section 2.2.3, the influence of stirring mode on fenton oxidation treatment effect is shown in fig.2.Influence of stirring method on $\mathrm{COD}_{\mathrm{Cr}}$ removal rate.

As can be seen from Fig.2, $\mathrm{COD}_{\mathrm{Cr}}$ of secondary sedimentation tank wastewater decreased under the same condition of aeration and blowing, and the removal rate of $\mathrm{COD}^{\mathrm{Cr}}$ was $9.3 \%$, while the removal rate of $\mathrm{COD}_{\mathrm{Cr}}$ was more than $55 \%$ in both aeration stirring and mechanical stirring fenton oxidation treatment, and the removal efficiency of $\mathrm{COD}_{\mathrm{Cr}}$ by aeration and stirring was $4.4 \%$ lower than that of mechanical stirring, so the volatilization of organic matter with low boiling point in wastewater could not play a leading role in aeration and agitation fenton oxidation treatment.

In addition, aeration stirring is a stirring method that forcibly dissolves the oxygen in the air into the water body and maintains the dissolved oxygen content in the water. It promotes the oxidation and decomposition of refractory organic matter to a certain extent and reduces the CODCr value of waste water. The mechanical stirring relies on the agitator to stir the waste water, which can better disperse the insoluble particles in the waste water and facilitate the flocculation and precipitation of organic matters. Therefore, the mechanical stirring method was adopted to treat the wastewater, and the removal rate of $\mathrm{CODCr}$ in the wastewater was the highest and the oxidation treatment effect was the best.

\subsubsection{Influence of adsorption-coagulation on oxidation effect after fenton oxidation}

As described in 2.2.4, $\mathrm{COD}_{\mathrm{Cr}}$ of supernatant was determined under different adsorption-coagulation conditions, and the effect of secondary treatment on fenton oxidation treatment was shown in fig. 3.

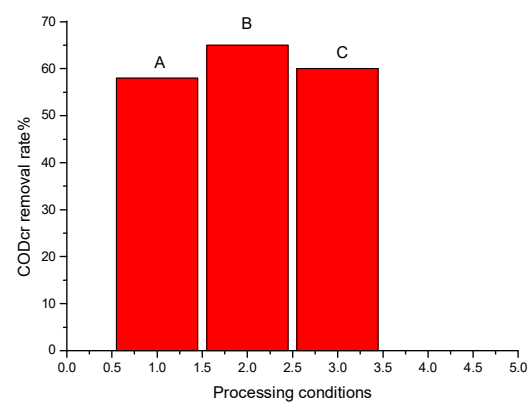

A:Fenton water

B: Fenton water-activated carbon adsorption-cogulation

C: Fenton water- cogulation

Fig. 3 Effects of different treatments on $\mathrm{COD}_{\mathrm{Cr}}$ removal rate

Fig. 3 shows that the removal rate of CODCr after fenton treatment of waste water is $59 \%$, the removal rate increases by $4.1 \%$ after the secondary treatment of coagulation precipitation, and the removal rate of CODCr after the secondary treatment of adsorption-coagulation is up to $64.5 \%$.

Fenton's reagent was oxidized, and fenton's reagent was oxidized, so fenton's reagent was oxidized. In the secondary treatment of coagulation and precipitation, the suspended matter in the water was effectively removed under the flocculation and precipitation of PAC and PAM, so the removal rate of $\mathrm{COD}_{\mathrm{Cr}}$ was also improved. In the secondary treatment of adsorption-coagulation, due to the strong adsorption of activated carbon itself, the refractory organic matter contained in the wastewater was completely precipitated, the water quality was rapidly improved, and the removal rate of $\mathrm{COD}_{\mathrm{Cr}}$ was further improved. Therefore, fenton effluent-activated carbon adsorption $1 \mathrm{~h}$-coagulation method was used for the secondary treatment of wastewater. The removal rate of $C O D_{\mathrm{Cr}}$ in wastewater was the highest, and fenton oxidation treatment had the best effect. 


\subsection{5 influence of optimal conditions on oxidation effect}

As described in $2.2 .5, \mathrm{COD}_{\mathrm{Cr}}$ of water samples was determined under the best conditions, and the treatment effect was shown in Table 2.

Table 2 Treatment effects under optimal conditions

\begin{tabular}{cccc}
\hline conditions & $\begin{array}{c}\mathrm{COD}_{\mathrm{Cr}} \\
\mathrm{mg} / \mathrm{L}\end{array}$ & $\begin{array}{c}\mathrm{COD}_{\mathrm{Cr}} \text { average } \\
\mathrm{mg} / \mathrm{L}\end{array}$ & $\begin{array}{c}\mathrm{COD}_{\mathrm{Cr}} \\
\text { Removal rate } \%\end{array}$ \\
\hline Best condition & 50.5 & 48.5 & 73.4 \\
\hline
\end{tabular}

Based on the above data, when the wastewater was treated under the optimal condition of fenton oxidation experiment, the total removal rate of $\mathrm{COD}_{\mathrm{Cr}}$ was up to $73.4 \%$, and the $\mathrm{COD}_{\mathrm{Cr}}$ value of wastewater was reduced from 183 to 48.5 , meeting the pollutant discharge standard and meeting the discharge standard, providing data support for better treatment of industrial wastewater.

\section{Conclusion}

Comprehensive research project the data above, we can know the sewage factory the second pond effluent water quality can be "fenton oxidation - and - coagulation sedimentation" oxidation method, through the "fenton oxidation - and - coagulation sedimentation treatment, when fixed hydrogen peroxide dosing quantity is $1.2 \mathrm{~mL} / \mathrm{L}$, $\mathrm{FeSO}_{4} \cdot 7 \mathrm{H}_{2} \mathrm{O}$ dosing quantity is $0.5 \%$, fenton reaction time is $4 \mathrm{~h}$, and adopts the mechanical mixing method, active carbon adsorption of $1 \mathrm{~h}$ - coagulation secondary treatment of removing effect is best, when the removal rate of $\mathrm{COD}_{\mathrm{Cr}}$ reached $73.4 \%$. Among them, the contribution rate of the wastewater itself to $\mathrm{COD}_{\mathrm{Cr}}$ removal was $9.3 \%$, and the mechanical stirring method was better than the aeration stirring method.

Meanwhile, from the perspective of economic benefits, the treatment costs are shown in Table 3 . It can be seen that this method can improve the removal rate of $\mathrm{COD}_{\mathrm{Cr}}$ and promote the discharge of waste water up to the standard. Fenton oxidation - neutralization - coagulation precipitation method can achieve better treatment effect, meet the economic benefits of sewage treatment plants, and provide data support for better treatment of industrial waste water.

Table 3 fenton oxidation treatment costs

\begin{tabular}{cccc}
\hline Drug kinds & $\begin{array}{c}\text { Unit price } \\
\text { yuan } / \mathrm{t}\end{array}$ & $\begin{array}{c}\text { The dosage } \\
\mathrm{g} / \mathrm{L}\end{array}$ & $\begin{array}{c}\text { Processing cost } \\
\text { yuan } / \mathrm{t}\end{array}$ \\
\hline Ferrous sulfate & 400 & 0.5 & 0.2 \\
$30 \%$ hydrogen peroxide solution & 1200 & 1.33 & 1.596 \\
PAC & 2000 & 0.2 & 0.4 \\
PAM & 9000 & 0.005 & 0.045 \\
$98 \%$ of sulfuric acid & 500 & 1 & 0.5 \\
lime & 500 & 0.5 & 0.25 \\
Sludge (dry) & 3000 & 0.1 & 0.3 \\
Total & & & 3.291 \\
\hline
\end{tabular}

\section{Acknowledgement}

The research is supported by a Project Funded by Innovation and entrepreneurship training program for college students in Jiangsu province (2019).

\section{Reference}

[1] He-tian Chen, Wei Ii, Ri-xin Ding, Feng Luo, Guan-ti Xie, Ming-zhu Miao. Discussion on the construction of intelligent operation platform for sewage treatment plant [J]. Water supply and drainage, 2016,42 (S1) : 292296.

[2] Zhan-peng Jiang, Hong-wei Yang. Environmental engineering (third edition)[M], Beijing: higher education press, 2003:73-74.

[3] Yong-ling Chen, Yi-ning Zheng, Dun-yu Zhu. Process design of sludge system in sewage treatment plant upgrade [J]. China water supply and drainage, 2013,29 (10) : 40-43.

[4] Xiao-dong Li, Jng Feng, Jie Liang, Qing CAI, Lu Huang, Lin Shi,Guang-ming Zeng. Research on optimization of secondary sedimentation tank based on numerical response surface method [J]. Journal of environmental science, 2012,32 (9) : 2279-2286.

[5]Environmental science and technology, 2011,34(6) : 163-166. (in Chinese with English abstract)

[6] Xin Liu, Yong Zheng, Mei-hua Fu, Li-juan Ma. Selection of sedimentation tank type in water purification station of water supply system of thermal power plant [J]. Environment and development, 2017,19 (1) : 98100

[7] Cong Zhao, Jing zhang. progress of fenton oxidation technology in wastewater treatment [J]. Environmental science and management, 2015, 39(5) : 83-87. (in Chinese)

[8] Qing-guo Chen, Mei Liu. Treatment of Oil Field Wastewater after Chemical Flooding by Fenton Oxidation 
Combined with Bio - degradation [J]. Journal of Meteorological and Environmental research, 2015, 6 (3) : 37 to 40 .

[9] Jing Wang, Zeng-feng. Yang. Application of Fenton oxidation in wastewater treatment [J]. Environmental science and technology, 2011,4 (11) : 104-108. (in Chinese)

[10]GB 6920-1986 water quality -- determination of $\mathrm{pH}$ value -- glass electrode method (S).

[11]GB 11903-1989 determination of water color (S).

[12]GB 11893-1989 water quality -- determination of total phosphorus -- ammonium molybdate spectrophotometric method (S).

[13]GB 11914-1989 chemical oxygen demand for water -- determination of dichromate method (S). 